\title{
Consolidation Theory for a Stone Column Composite Foundation under Multistage Loading
}

\author{
Shenggen Huang, ${ }^{1}$ Yingtao Feng, ${ }^{1}$ Hao Liu, ${ }^{1}$ Wenbing Wu, ${ }^{1,2}$ and Guoxiong Mei ${ }^{2}$ \\ ${ }^{1}$ Engineering Research Centre of Rock-Soil Drilling \& Excavation and Protection, Ministry of Education, \\ China University of Geosciences, Wuhan, Hubei 430074, China \\ ${ }^{2}$ College of Civil Engineering and Architecture, Guangxi University, Nanning, Guangxi 530004, China
}

Correspondence should be addressed to Wenbing Wu; zjuwwb1126@163.com

Received 30 November 2015; Revised 19 March 2016; Accepted 5 May 2016

Academic Editor: Pablo Mira

Copyright (C) 2016 Shenggen Huang et al. This is an open access article distributed under the Creative Commons Attribution License, which permits unrestricted use, distribution, and reproduction in any medium, provided the original work is properly cited.

\begin{abstract}
The consolidation theories considering instant load cannot fully reveal the consolidation mechanism of a stone column composite foundation used in the expressway embankments due to the time effect of loading; that is, the expressway embankments are often constructed in several stages for a long time. Meanwhile, owing to the special property that the pile-soil stress ratio is larger than 1, the consolidation theory for sand drain well foundation cannot be used directly in the consolidation analysis of stone column composite foundation. Based on the principle that the vertical load applied on the composite foundation is shared by the stone column and the surrounding soil, the governing solutions for the stone column composite foundation under a multistage load are established. By virtue of the separation of variables, the corresponding solutions of degree of consolidation for loading stage and maintaining load stage are derived separately. According to the Carrillo theorem, the solution for the average total degree of consolidation of entire composite foundation is also obtained. Finally, the reasonableness of the present solution has been verified by comparing the consolidation curve calculated by the present solution with that measured by site test.
\end{abstract}

\section{Introduction}

Due to the much higher permeability compared to its surrounding and underlying untreated soils, the granular columns are widely applied in composite foundation reinforcement all over the world. A system of stone columns combined with preloading, which is one of the most commonly used granular columns, has attracted increasing attention in the past decades, especially in enforcing the embankments of expressway. The stone columns can result in a lot of beneficial effects on the surrounding soils, such as improving the bearing capacity of composite foundation, reducing the total and differential settlements of composite foundation, and accelerating the consolidation process of surrounding soil.

The consolidation theory of granular column composite foundation can date back to the precious works of Carrillo [1] and Barron [2], in which the consolidation properties of a sand drain well foundation were theoretically analyzed. The subject of the consolidation process of a sand drain well foundation was later pursued extensively by Balaam and Booker [3], Hird et al. [4], Xie [5], Chen [6], and others for more and more engineering conditions (including boundary conditions and initial conditions). The consolidation process of stone column composite foundation is similar to that of sand drain well foundation, but there are still many differences on the consolidation mechanism between these two foundations. As we know, the modulus of sand drain well can be approximatively equal to that of its surrounding soil. However, the modulus of stone column is totally different from that of its surrounding soil; that is, the modulus of stone column is much larger than the modulus of its surrounding soil. It is also noteworthy that the larger the stone column-soil modulus ratio, the more the differences in the consolidation mechanism between these two composite foundations [3]. Therefore, the consolidation theory of sand drain well foundation cannot be used directly to design stone column composite foundation, for the influence of the stone 
column-soil modulus ratio on the consolidation process of column composite foundation is still not clear.

In the last few decades, considerable strides have been made in developing the consolidation theory for a stone column composite foundation. Han and Ye [7] presented an analytical solution for calculating the consolidation rates of a stone column reinforced foundation by considering the smear and well resistance effects. Zhu and Yin [8] derived an analytical solution for the consolidation analysis of soil with vertical and horizontal drainage system and ramp loading. Wang [9] proposed a consolidation solution for a stone column reinforced ground under various forms of time-dependent loading. By taking into account the lateral deformation of the stone column, Castro and Sagaseta [10,11] established a series of solutions to investigate the influence of column deformation on the consolidation process of soil. Soon later, Castro et al. [12] studied the changes in the state of soil due to stone column installation and the influences of stone column installation on settlement reduction through numerical simulations. Considering a linear variation of horizontal permeability coefficient within the disturbed soil zone along with a time- and depth-dependent stress increment caused by external, Xie et al. [13] gave a general analytical solution for the consolidation process of a stone column composite foundation. Following this work, Lu et al. [14, 15] built a series of analytical solutions for the consolidation of a composite foundation reinforced by an impervious column and stone column for different engineering conditions. Zhang et al. [16] deduced an accurate solution for the consolidation of composite foundation improved by geosynthetic-encased stone columns, in which the deformations and water flows in both vertical and radial directions in the element were taken into account. Tang et al. [17] proposed a closed-form solution for the consolidation with a vertical drain system based on a three-layered soil model. Yang et al. [18] obtained an analytical solution about a composite foundation reinforced by partially penetrated impervious columns based on a doublelayer subsoil ground model. Liu et al. [19] used a quasianalytical method to investigate the equal-strain consolidation problem, in which the multilayered soil with a vertical drain system and both vertical and radial drainage conditions were considered. By utilizing unit cell finite element analyses, Hosseinpour et al. [20] investigated the bearing capacity and settlement of a granular column composite foundation reinforced by geosynthetics using encasement and laminated disks.

As stated in these aforementioned works, many achievements have been reported in the literature for the consolidation of a stone column composite foundation. However, these solutions are not suitable for the consolidation analysis of a stone column composite foundation which is used in the enforcement of expressway embankments. As well known, the expressway embankments are often constructed in several stages during a long time, which means that the relationship between loading and time should be an important factor in the consolidation analysis of the composite foundation of expressway embankment. Due to the time effect of loading, the calculating error cannot be ignored when utilizing the aforementioned consolidation theories to

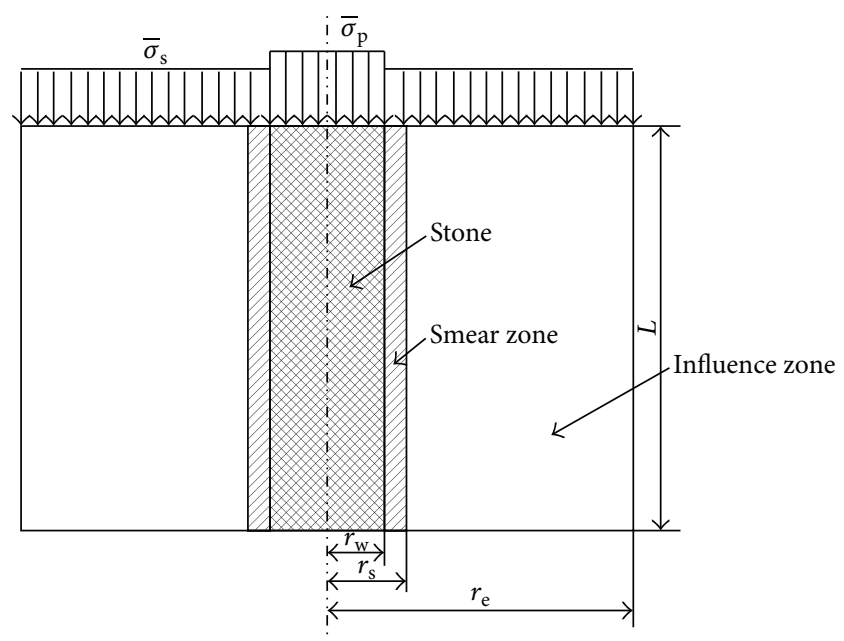

Figure 1: Calculation model of a stone column composite foundation.

predict the consolidation process of stone column composite foundation in expressway embankments [21]. To remedy the shortcoming of the existing theories assuming the loading is constant, a multistage load is used to simulate the boundary condition of expressway embankments in this paper. Then, a closed-form solution for the consolidation process of a stone column composite foundation employed in the enforcement of expressway embankments is derived based on the basic idea of calculation method for a sand drain well foundation, which divides the consolidation problem into two parts, that is, radial consolidation part and vertical consolidation part. The general degree of consolidation of a stone column composite foundation is also obtained by means of Carrillo theorem [1].

\section{Solution of Radial Consolidation}

2.1. Basic Assumptions. As seen in Figure 1, the stone column composite foundation is simulated by a cylindrical consolidation model consisting of stone column, smear zone, and surrounding soil from inside to outside. $L$ denotes the length of stone column and $r_{\mathrm{w}}, r_{\mathrm{s}}$, and $r_{\mathrm{e}}$ represent the radii of stone column, smear zone, and influence zone, respectively. $\bar{\sigma}_{\mathrm{p}}$ and $\bar{\sigma}_{\mathrm{s}}$ indicate the average load applied on the top of stone column and surrounding soil, respectively. The following assumptions are made during the analysis:

(1) Darcy's law is valid.

(2) The assumption of equal vertical strains is adopted; that is, there is no lateral deformation in the stone column composite foundation.

(3) The outer boundary of influence zone is impermeable and incompressible, which means that the soil area outside influence zone is not affected by the consolidation process of stone column composite foundation.

(4) The variation of the excess pore pressure along the radial direction is not considered in the stone column. 
(5) The water quantity flowing into the stone column is equal to that flowing out of the stone column.

2.2. Governing Equations. In the calculation model as shown in Figure $1, k_{\mathrm{h}}$ and $k_{\mathrm{v}}$ are defined as the radial and vertical permeability coefficients of the surrounding soil, respectively. $k_{\mathrm{s}}$ and $k_{\mathrm{w}}$ are denoted as the radial permeability coefficient of the smear zone and permeability coefficient of stone column, respectively. The radius ratio of the influence zone to the stone column can be described as $n=r_{\mathrm{e}} / r_{\mathrm{w}}$, and the radius ratio of the smear zone to the stone column can be denoted as $s=$ $r_{\mathrm{s}} / r_{\mathrm{w}}$. The vertical load acting on the composite foundation is shared by the stone column and the surrounding soil, and the equilibrium equation of these loads can be written as follows:

$$
\bar{\sigma}_{\mathrm{p}} A_{\mathrm{p}}+\bar{\sigma}_{\mathrm{s}} A_{\mathrm{s}}=P A,
$$

where $A_{\mathrm{p}}, A_{\mathrm{s}}$, and $A$ represent the area of stone column, surrounding soil, and influence zone, respectively. $P$ denotes the vertical load acting on the composite foundation.

Substituting $n=r_{\mathrm{e}} / r_{\mathrm{w}}$ into (1) yields

$$
\bar{\sigma}_{\mathrm{p}}+\left(n^{2}-1\right) \bar{\sigma}_{\mathrm{s}}=P n^{2} \text {. }
$$

Defining $b=\bar{\sigma}_{\mathrm{p}} / \bar{\sigma}_{\mathrm{s}}$ and substituting it into (2) gives

$$
\bar{\sigma}_{\mathrm{s}}\left(b+n^{2}-1\right)=P n^{2} .
$$

Combining the principle of effective stress $\bar{\sigma}_{\mathrm{s}}=\bar{\sigma}_{\mathrm{s}}^{\prime}+\bar{u}_{\mathrm{r}}$ and Hooke's Law $\bar{\sigma}_{\mathrm{s}}^{\prime}=E_{\mathrm{s}} \varepsilon_{\mathrm{v}}$, the rate of vertical strain of the column and soil can be expressed as [21]

$$
\frac{\partial \varepsilon_{\mathrm{v}}}{\partial t}=\frac{C_{\mathrm{b}}}{E_{\mathrm{s}}} \frac{\partial P}{\partial t}-\frac{1}{E_{\mathrm{s}}} \frac{\partial \bar{u}_{\mathrm{r}}}{\partial t},
$$

where $C_{\mathrm{b}}=n^{2} /\left(b+n^{2}-1\right) \cdot \varepsilon_{\mathrm{v}}$ depicts the vertical strain of the column and the surrounding soil when only considering the radial penetration. $\bar{u}_{\mathrm{r}}$ is the average excess pore-water pressure at any depth in the composite foundation when only considering the radial penetration.

The single-stage construction load applied on the top of stone column composite foundation can be simulated by a single-stage loading model as shown in Figure 2, whose expression can be written as follows:

$$
\frac{\partial P}{\partial t}= \begin{cases}k_{\mathrm{e}}, & 0 \leq t \leq t_{\mathrm{e}} \\ 0, & t>t_{\mathrm{e}}\end{cases}
$$

where $t_{\mathrm{e}}, P_{\mathrm{e}}$, and $k_{\mathrm{e}}$ denote the duration time of loading, ultimate load, and slope of loading curve, respectively.

Substituting (5) into (4) gives

$$
\frac{\partial \varepsilon_{\mathrm{v}}}{\partial t}=\frac{C_{\mathrm{b}}}{E_{\mathrm{s}}} k_{\mathrm{e}}-\frac{1}{E_{\mathrm{s}}} \frac{\partial \bar{u}_{\mathrm{r}}}{\partial t}
$$

Following the researches reported by Xie [5] and Chen [6], the consolidation equations for the surrounding soil can be written as shown in (7)-(10) based on Darcy's Law and

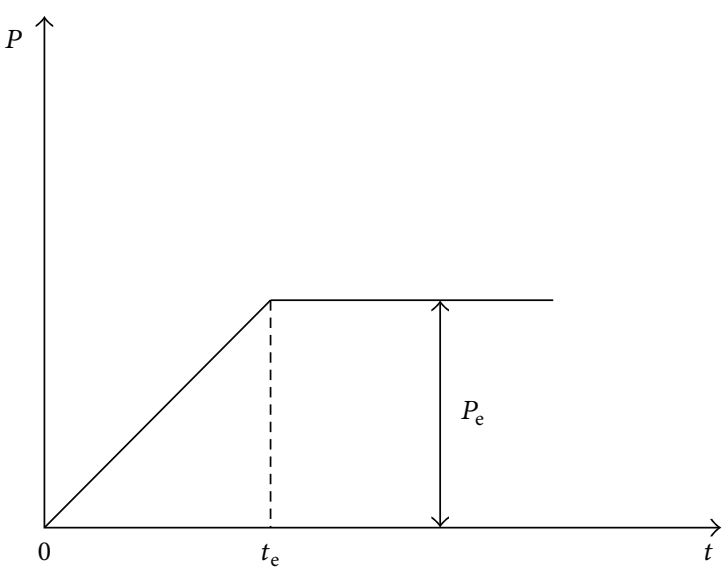

FIGURE 2: Single-stage loading model.

the principle that the change of water quantity is equal to the volume change in the soil:

$$
\begin{aligned}
-\frac{k_{\mathrm{s}}}{\gamma_{\mathrm{w}}} \frac{1}{r} \frac{\partial}{\partial r}\left(r \frac{\partial u_{\mathrm{r}}}{\partial r}\right) & =\frac{\partial \varepsilon_{\mathrm{v}}}{\partial t}, \quad r_{\mathrm{w}} \leq r \leq r_{\mathrm{s}}, \\
-\frac{k_{\mathrm{h}}}{\gamma_{\mathrm{w}}} \frac{1}{r} \frac{\partial}{\partial r}\left(r \frac{\partial u_{\mathrm{r}}}{\partial r}\right) & =\frac{\partial \varepsilon_{\mathrm{v}}}{\partial t}, \quad r_{\mathrm{s}} \leq r \leq r_{\mathrm{e}}, \\
\left.2 \pi r_{\mathrm{w}} \mathrm{d} z \frac{k_{\mathrm{s}}}{\gamma_{\mathrm{w}}} \frac{\partial u_{\mathrm{r}}}{\partial r}\right|_{r=r_{\mathrm{w}}} & =-\pi r_{\mathrm{w}}^{2} \mathrm{~d} z \frac{k_{\mathrm{w}}}{\gamma_{\mathrm{w}}} \frac{\partial^{2} u_{\mathrm{w}}}{\partial z^{2}}, \\
\bar{u}_{\mathrm{r}} & =\int_{r_{\mathrm{w}}}^{r_{\mathrm{e}}} \frac{2 \pi r u_{\mathrm{r}} \mathrm{d} r}{\pi\left(r_{\mathrm{e}}^{2}-r_{\mathrm{w}}^{2}\right)},
\end{aligned}
$$

where $u_{\mathrm{r}}$ and $u_{\mathrm{w}}$ represent the average excess pore-water pressure at any point in the composite foundation and the average excess pore-water pressure at any depth in the stone column when only considering the radial penetration, respectively. $t$ is the loading time.

Then, the boundary conditions and initial conditions can be written as follows:

$$
\begin{aligned}
\left.\frac{\partial u_{\mathrm{r}}}{\partial r}\right|_{r=r_{\mathrm{e}}} & =0, \\
\left.u_{\mathrm{w}}\right|_{z=0} & =0, \\
\left.\frac{\partial u_{\mathrm{w}}}{\partial z}\right|_{z=L} & =0, \\
\left.\bar{u}_{\mathrm{r}}\right|_{t=0} & =u_{\mathrm{r} 0}=P, \\
\left.u_{\mathrm{r}}\right|_{r=r_{\mathrm{w}}} & =u_{\mathrm{w}} .
\end{aligned}
$$

2.3. Solutions of the Governing Equations. By means of (11a) and suitable manipulations, (7) and (8) can be rewritten as

$$
\begin{array}{ll}
\frac{\partial u_{\mathrm{r}}}{\partial r}=\frac{\gamma_{\mathrm{w}}}{2 k_{\mathrm{s}}}\left(\frac{r_{\mathrm{e}}^{2}}{r}-r\right) \frac{\partial \varepsilon_{\mathrm{v}}}{\partial t}, & r_{\mathrm{w}} \leq r \leq r_{\mathrm{s}}, \\
\frac{\partial u_{\mathrm{r}}}{\partial r}=\frac{\gamma_{\mathrm{w}}}{2 k_{\mathrm{h}}}\left(\frac{r_{\mathrm{e}}^{2}}{r}-r\right) \frac{\partial \varepsilon_{\mathrm{v}}}{\partial t}, & r_{\mathrm{s}} \leq r \leq r_{\mathrm{e}} .
\end{array}
$$


By integrating (12) and (13) with respective to $r$, the following equations are obtained:

$$
\begin{aligned}
& u_{\mathrm{r}}=-\left[\frac{\gamma_{\mathrm{w}}}{2 k_{\mathrm{s}}}\left(r_{\mathrm{e}}^{2} \ln \frac{r}{r_{\mathrm{w}}}-\frac{r^{2}-r_{\mathrm{w}}^{2}}{2}\right) \frac{\partial \varepsilon_{\mathrm{v}}}{\partial t}\right]+u_{\mathrm{w}}, r_{\mathrm{w}} \leq r \leq r_{\mathrm{s}}, \\
& u_{\mathrm{r}}=-\left[\frac{\gamma_{\mathrm{w}}}{2 k_{\mathrm{h}}}\left(r_{\mathrm{e}}^{2} \ln \frac{r}{r_{\mathrm{e}}}-\frac{r^{2}-r_{\mathrm{s}}^{2}}{2}\right)\right. \\
&\left.+\frac{\gamma_{\mathrm{w}}}{2 k_{\mathrm{s}}}\left(r_{\mathrm{e}}^{2} \ln s-\frac{r_{\mathrm{s}}^{2}-r_{\mathrm{w}}^{2}}{2}\right)\right] \frac{\partial \varepsilon_{\mathrm{v}}}{\partial t}+u_{\mathrm{w}}, \quad \\
& \quad r_{\mathrm{s}} \leq r \leq r_{\mathrm{e}} .
\end{aligned}
$$

Combining (10), (14), and (15), the following equation can be derived:

$$
\bar{u}_{\mathrm{r}}=\frac{\gamma_{\mathrm{w}} r_{\mathrm{e}}^{2}}{2 k_{\mathrm{h}}} F_{\mathrm{a}} \frac{\partial \varepsilon_{\mathrm{v}}}{\partial t}+u_{\mathrm{w}}
$$

where

$$
\begin{aligned}
F_{\mathrm{a}}= & \left(\ln \frac{n}{s}+\frac{k_{\mathrm{h}}}{k_{\mathrm{s}}} \ln s-\frac{3}{4}\right) \frac{n^{2}}{n^{2}-1} \\
& +\frac{s^{2}}{n^{2}-1}\left(1-\frac{k_{\mathrm{h}}}{k_{\mathrm{s}}}\right)\left(1-\frac{s^{2}}{4 n^{2}}\right) \\
& +\frac{k_{\mathrm{h}}}{k_{\mathrm{s}}} \frac{1}{n^{2}-1}\left(1-\frac{1}{4 n^{2}}\right) .
\end{aligned}
$$

Similarly, combining (9), (14), and (15), one can obtain

$$
\begin{aligned}
\frac{\partial^{2} u_{\mathrm{w}}}{\partial z^{2}} & =\frac{2 k_{\mathrm{s}}}{r_{\mathrm{w}} k_{\mathrm{w}}}\left[\frac{\gamma_{\mathrm{w}}}{2 k_{\mathrm{s}}}\left(\frac{r_{\mathrm{e}}^{2}}{r_{\mathrm{w}}}-r_{\mathrm{w}}\right) \frac{\partial \varepsilon_{\mathrm{v}}}{\partial t}\right] \\
& =\frac{r_{\mathrm{w}}}{k_{\mathrm{w}}}\left(n^{2}-1\right) \frac{\partial \varepsilon_{\mathrm{v}}}{\partial t} .
\end{aligned}
$$

Substituting (16) into (18) yields

$$
\frac{\partial^{2} u_{\mathrm{w}}}{\partial z^{2}}=\beta^{2}\left(\bar{u}_{\mathrm{r}}-u_{\mathrm{w}}\right),
$$

where

$$
\beta^{2}=\frac{8 k_{\mathrm{h}}\left(n^{2}-1\right)}{k_{\mathrm{w}} d_{\mathrm{e}}^{2} F_{\mathrm{a}}}
$$

in which $d_{\mathrm{e}}=2 r_{\mathrm{e}}$ is the diameter of influence zone.

Combining (6) and (16), the following relation can be obtained:

$$
\frac{\partial \bar{u}_{\mathrm{r}}}{\partial t}-C_{\mathrm{b}} k_{\mathrm{e}}=-\alpha\left(\bar{u}_{\mathrm{r}}-u_{\mathrm{w}}\right)
$$

where

$$
\alpha=\frac{2 k_{\mathrm{h}} E_{\mathrm{s}}}{\gamma_{\mathrm{w}} r_{\mathrm{e}}^{2} F_{\mathrm{a}}}
$$

Combining (19) and (21), the following equation can be derived:

$$
\frac{\partial^{3} u_{\mathrm{w}}}{\partial z^{2} \partial t}+\alpha \frac{\partial^{2} u_{\mathrm{w}}}{\partial z^{2}}-\beta^{2} \frac{\partial u_{\mathrm{w}}}{\partial t}+C_{\mathrm{b}} \beta^{2} k_{\mathrm{e}}=0 .
$$

By means of the separation of variables, the solution of (23) can be derived as [21]

$$
\begin{aligned}
u_{\mathrm{w}} & =-\frac{1+\lambda \eta}{\alpha \lambda}\left(C(t) \mathrm{e}^{-(\lambda \alpha /(1+\lambda \eta))}+D\right) \\
& {\left[A \sin \frac{\lambda \beta^{2}}{1-\lambda(1-\eta)} z+B \cos \frac{\lambda \beta^{2}}{1-\lambda(1-\eta)} z\right], }
\end{aligned}
$$

where $\eta, \lambda, D$, and $C(t)$ are coefficients, in which $D$ and $C(t)$ are determined by $C_{\mathrm{b}} \beta^{2} k_{\mathrm{e}}$. $A$ and $B$ are undetermined constants which can be obtained via boundary conditions or assumptions.

Combining assumption (3), (11b), and (1lc), one can obtain

$$
B=0,
$$

$$
A \frac{\lambda \beta^{2}}{1-\lambda(1-\eta)} \cos \frac{\lambda \beta^{2}}{1-\lambda(1-\eta)} L=0 .
$$

Letting $\eta=1 / 2$ [21], one can derive

$$
\begin{aligned}
\lambda=\frac{2 M}{M+2 \beta^{2} L}, & \\
& M=\frac{1}{2 \pi(2 m+1)}, \quad(m=0,1,2,3, \ldots) .
\end{aligned}
$$

Substituting (25) and (26) into (24), the particular solution of $u_{\mathrm{w}}$ can be given as

$$
\begin{aligned}
u_{\mathrm{w}}= & \sum_{m=0}^{\infty} A_{m} \frac{M+\beta^{2} L}{\alpha M}\left(C(t) \mathrm{e}^{-\left(\alpha M /\left(M+\beta^{2} L\right)\right) t}+D\right) \\
& \cdot \sin \frac{M}{L} z .
\end{aligned}
$$

In the following section, the general solution of $\bar{u}_{\mathrm{r}}$ is theoretically discussed under two kinds of loading condition, that is, single-stage loading and multistage loading.

\section{(a) Single-Stage Loading Consists of Two Stages}

(a1) Loading Stage. Substituting (27) into (23) and combining (11d), (11e), and (19), the following coefficients can be easily determined as follows:

$$
\begin{aligned}
A_{m} & =\frac{2 L^{2} \beta^{2}\left(\rho_{m} u_{\mathrm{r} 0}-C_{\mathrm{b}} k_{\mathrm{e}}\right) \gamma_{\mathrm{t}}}{\alpha M^{2}}, \\
D & =\frac{C_{\mathrm{b}} k_{\mathrm{e}}}{\rho_{m} u_{\mathrm{r} 0}-C_{\mathrm{b}} k_{\mathrm{e}}}, \\
C(t) & =\mathrm{e}^{-\left(\rho_{m}-\gamma_{\mathrm{t}}\right) t},
\end{aligned}
$$


where

$$
\begin{aligned}
& \rho_{m}=\frac{\alpha M^{2}}{M^{2}+\beta^{2} L^{2}}, \\
& \gamma_{\mathrm{t}}=\frac{\alpha M}{M+\beta^{2} L} .
\end{aligned}
$$

By substituting (28)-(29) into the expressions of $u_{\mathrm{w}}$ and $\bar{u}_{\mathrm{r}}$, the following equations can be derived:

$$
\begin{aligned}
u_{\mathrm{w}} & =\sum_{m=0}^{\infty} \frac{2 L^{2} \beta^{2}\left(\rho_{m} u_{\mathrm{r} 0}-C_{\mathrm{b}} k_{\mathrm{e}}\right)}{M^{3}}\left(\mathrm{e}^{-\rho_{m} t}\right. \\
& \left.+\frac{C_{\mathrm{b}} k_{\mathrm{e}}}{\rho_{m} u_{\mathrm{r} 0}-C_{\mathrm{b}} k_{\mathrm{e}}}\right) \sin \frac{M}{L} z, \\
\bar{u}_{\mathrm{r}} & =\sum_{m=0}^{\infty} \frac{2\left(\rho_{m} u_{\mathrm{r} 0}-C_{\mathrm{b}} k_{\mathrm{e}}\right)}{M \rho_{m}}\left(\mathrm{e}^{-\rho_{m} t}+\frac{C_{\mathrm{b}} k_{\mathrm{e}}}{\rho_{m} u_{\mathrm{r} 0}-C_{\mathrm{b}} k_{\mathrm{e}}}\right) \\
& \cdot \sin \frac{M}{L} z .
\end{aligned}
$$

Substituting $u_{\mathrm{r} 0}=0$ into (31) yields

$$
\bar{u}_{\mathrm{r}}=\sum_{m=0}^{\infty} \frac{2 C_{\mathrm{b}} k_{\mathrm{e}}}{M \rho_{m}}\left(1-\mathrm{e}^{-\rho_{m} t}\right) \sin \frac{M}{L} z .
$$

(a2) Maintaining Load Stage. During the maintaining load stage, $k_{\mathrm{e}}$ is equal to zero. According to the phenomenon that the average excess pore-water pressures within the column and the entire composite foundation are identical when $t=t_{\mathrm{e}}$, the following expressions can be obtained:

$$
\begin{aligned}
& u_{\mathrm{w}}=\sum_{m=0}^{\infty} \frac{2 L^{2} \beta^{2} C_{\mathrm{b}} k_{\mathrm{e}}}{M^{3}}\left(1-\mathrm{e}^{-\rho_{m} t}\right) \mathrm{e}^{-\rho_{m}\left(t-t_{\mathrm{e}}\right)} \sin \frac{M}{L} z, \\
& \bar{u}_{\mathrm{r}}=\sum_{m=0}^{\infty} \frac{2 C_{\mathrm{b}} k_{\mathrm{e}}}{M \rho_{m}}\left(1-\mathrm{e}^{-\rho_{m} t}\right) \mathrm{e}^{-\rho_{m}\left(t-t_{\mathrm{e}}\right)} \sin \frac{M}{L} z .
\end{aligned}
$$

(b) Multistage Loading. According to the construction process of embankment of expressway, the construction load can be assumed to be a model of multistage load illustrated in Figure 3. In this model, there are a total of $n$ loading grades, in which $t_{(2 i-1)}, t_{(2 i-2)}$, and $K_{\mathrm{e} i}$ represent the starting time, finishing time, and loading rate of the $i$ th grade of loading, respectively.

By utilizing the similar solving process of the singlestage loading and assuming that the average excess porewater pressures within the column and the entire composite foundation are identical during the constant load stage, the solution of $\bar{u}_{\mathrm{r}}$ can be easily derived as follows:

(b1) For loading stage,

$$
\begin{aligned}
\bar{u}_{\mathrm{r}} & =\sum_{m=0}^{\infty} \frac{2 C_{\mathrm{b}}}{M \rho_{m}} \\
& \cdot \sin \frac{M z}{L}\left[\sum_{i=1}^{n-1} K_{\mathrm{ei}}\left(\mathrm{e}^{-\rho_{m}\left(t-t_{(2 i-1)}\right)}-\mathrm{e}^{-\rho_{m}\left(t-t_{(2 i-2)}\right)}\right)\right. \\
& \left.+K_{\mathrm{en}}\left(1-\mathrm{e}^{-\rho_{m}\left(t-t_{(2 n-2)}\right)}\right)\right], \quad t_{(2 i-2)}<t \leq t_{(2 i-1)} .
\end{aligned}
$$

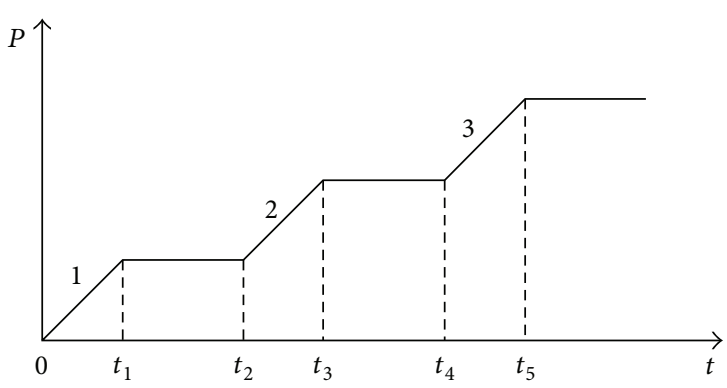

Figure 3: Multistage loading model.

(b2) For maintaining load stage,

$$
\begin{aligned}
& \bar{u}_{\mathrm{r}}=\sum_{m=0}^{\infty} \frac{2 C_{\mathrm{b}}}{M \rho_{m}} \\
& \cdot \sin \frac{M z}{L}\left[\sum_{i=1}^{n} K_{\mathrm{e} i}\left(\mathrm{e}^{-\rho_{m}\left(t-t_{(2 i-1)}\right)}-\mathrm{e}^{-\rho_{m}\left(t-t_{(2 i-2)}\right)}\right)\right], \\
& t_{(2 i-1)}<t .
\end{aligned}
$$

2.4. Degree of Radial Consolidation. The consolidation and deformation of the stone column are taken into consideration in this study. Therefore, the average degree of radial consolidation is defined as the ratio of the average effective stress to the total stress in the composite foundation as follows:

$$
U_{\mathrm{r}}=\frac{P(t)-\bar{u}_{\mathrm{r}}}{P_{n}}
$$

where $U_{\mathrm{r}}, P(t)$, and $P_{n}$ denote the degree of radial consolidation at any point in the composite foundation, the load at time $t$, and the ultimate loading.

The average degree of radial consolidation within the entire composite foundation can be derived as follows:

(1) For loading stage,

$$
\begin{aligned}
\bar{U}_{\mathrm{r}}= & \frac{\int_{0}^{L} U_{\mathrm{r}} \mathrm{d} z}{L} \\
= & \frac{P(t)}{P_{n}} \\
& -\frac{1}{P_{n}} \sum_{i=1}^{n-1} \frac{2 C_{\mathrm{b}}}{M^{2} \rho_{m}} K_{\mathrm{ei}}\left(\mathrm{e}^{-\rho_{m}\left(t-t_{(2 i-1)}\right)}-\mathrm{e}^{-\rho_{m}\left(t-t_{(2 i-2)}\right)}\right) \\
& +K_{\mathrm{en}}\left(1-\mathrm{e}^{-\rho_{m}\left(t-t_{(2 n-2)}\right)}\right) .
\end{aligned}
$$


(2) For maintaining load stage,

$$
\begin{aligned}
\bar{U}_{\mathrm{r}} & =\frac{P(t)}{P_{n}}-\frac{1}{P_{n}} \\
& \cdot \sum_{m=0}^{\infty} \frac{2 C_{\mathrm{b}}}{M \rho_{m}} \sin \frac{M z}{L}\left[\sum_{i=1}^{n} K_{\mathrm{ei}}\left(\mathrm{e}^{-\rho_{m}\left(t-t_{(2 i-1)}\right)}-\mathrm{e}^{-\rho_{m}\left(t-t_{(2 i-2)}\right)}\right)\right] .
\end{aligned}
$$

\section{Solution of Vertical Consolidation}

3.1. Basic Assumptions. Similar to the analytical process of radial consolidation, the following assumptions are adopted during the study:

(1) The soil is homogeneous, saturated, and elastic.

(2) Darcy's law is obeyed and the permeability coefficient of the soil is constant in the process of consolidation.

(3) The vertical load acting on the composite foundation is carried by both the stone column and surrounding soil, whose relation can be expressed as (1).

(4) The lateral deformation in stone column is not considered.
3.2. Governing Equations and Solutions. In the same derivation process of (6), the following equation can be obtained:

$$
\frac{\partial \varepsilon_{\mathrm{v}}}{\partial t}=\frac{C_{\mathrm{b}}}{E_{\mathrm{s}}} k_{\mathrm{e}}-\frac{1}{E_{\mathrm{s}}} \frac{\partial u}{\partial t} .
$$
yields

Substituting (39) into Terzaghi's Consolidation Equation

$$
\frac{k_{\mathrm{v}} E_{\mathrm{s}}}{\gamma_{\mathrm{w}}} \frac{\partial^{2} u}{\partial z^{2}}=\frac{\partial u}{\partial t}-C_{\mathrm{b}} K_{\mathrm{e}} .
$$

Similarly, the boundary conditions and initial conditions can be summarized as follows:

$$
\begin{aligned}
\left.u\right|_{t=0} & =u_{\mathrm{r} 0}, \\
\left.u\right|_{z=0} & =0, \\
\text { Single drainage: }\left.\frac{\partial u}{\partial z}\right|_{z=L} & =0, \\
\text { Double drainage: }\left.u\right|_{z=L} & =0
\end{aligned}
$$

Similar to the derivation process of the solution of $\bar{u}_{\mathrm{r}}$, the solution of $u$ can be easily derived by virtue of the separation of variables as follows:

(1) For loading stage,

$$
\begin{array}{r}
u=\sum_{m=0}^{\infty} \frac{2 C_{\mathrm{b}}}{M T_{m}} \sin \frac{M z}{L}\left[\sum_{i=1}^{n-1} K_{\mathrm{e} i}\left(\mathrm{e}^{-T_{m}\left(t-t_{(2 i-1)}\right)}-\mathrm{e}^{-T_{m}\left(t-t_{(2 i-2)}\right)}\right)+K_{\mathrm{en}}\left(1-\mathrm{e}^{-T_{m}\left(t-t_{(2 n-2)}\right)}\right)\right] \\
t_{(2 i-2)}<t \leq t_{(2 i-1)}
\end{array}
$$

For single drainage: $M=\frac{1}{2} \pi(2 m+1), \quad m=0,1,2,3, \ldots$

For double drainage: $M=m \pi, \quad m=0,1,2,3, \ldots$

(2) For maintaining load stage,

$$
\begin{aligned}
u & =\sum_{m=0}^{\infty} \frac{2 C_{\mathrm{b}}}{M T_{m}} \sin \frac{M z}{L} \\
& \cdot\left[\sum_{i=1}^{n} K_{\mathrm{e} i}\left(\mathrm{e}^{-T_{m}\left(t-t_{(2 i-1)}\right)}-\mathrm{e}^{-T_{m}\left(t-t_{(2 i-2)}\right)}\right)\right],
\end{aligned}
$$$$
t_{(2 i-1)}<t
$$

For single drainage: $M=\frac{1}{2} \pi(2 m+1)$,

$$
m=0,1,2,3, \ldots
$$

For double drainage: $M=m \pi, \quad m=0,1,2,3, \ldots$

3.3. Degree of Vertical Consolidation. Following the same definition of (36), the average degree of vertical consolidation within the entire composite foundation can be written as follows:
(1) For loading stage,

$$
\begin{aligned}
\bar{U}_{\mathrm{z}} & =\frac{\int_{0}^{L} U_{z} \mathrm{~d} z}{L}=\frac{P(t)}{P_{n}}-\frac{1}{P_{n}} \sum_{m=0}^{\infty} \frac{2 C_{\mathrm{b}}}{M^{2} T_{m}} \sin \frac{M z}{L} \\
& \cdot\left[\sum_{i=1}^{n-1} K_{\mathrm{e} i}\left(\mathrm{e}^{-T_{m}\left(t-t_{(2 i-1)}\right)}-\mathrm{e}^{-T_{m}\left(t-t_{(2 i-2)}\right)}\right)\right. \\
& \left.+K_{\mathrm{en}}\left(1-\mathrm{e}^{-T_{m}\left(t-t_{(2 n-2)}\right)}\right)\right] .
\end{aligned}
$$

(2) For maintaining load stage,

$$
\begin{gathered}
\bar{U}_{\mathrm{z}}=\frac{\int_{0}^{L} U_{z} \mathrm{~d} z}{L}=\frac{P(t)}{P_{n}}-\frac{1}{P_{n}} \sum_{m=0}^{\infty} \frac{2 C_{\mathrm{b}}}{M^{2} T_{m}} \sin \frac{M z}{L} \\
\cdot\left[\sum_{i=1}^{n} K_{\mathrm{e} i}\left(\mathrm{e}^{-T_{m}\left(t-t_{(2 i-1)}\right)}-\mathrm{e}^{-T_{m}\left(t-t_{(2 i-2)}\right)}\right)\right] .
\end{gathered}
$$


TABLE 1: Parameters of the soil profile of section $k 60+730$.

\begin{tabular}{|c|c|c|c|c|c|c|}
\hline Soil layers & Thickness/m & Soil state & $\begin{array}{c}\text { Compression } \\
\text { modulus/MPa }\end{array}$ & Compressibility/MPa ${ }^{-1}$ & Void ratio & $\begin{array}{c}\text { Permeability } \\
\text { coefficient } / \mathrm{m} \cdot \mathrm{d}^{-1}\end{array}$ \\
\hline 1 , mild clay & 0.5 & $\begin{array}{c}\text { Soft plastic or flow } \\
\text { plastic }\end{array}$ & 3.5 & 0.53 & 0.697 & $5 \times 10^{-5}$ \\
\hline 2 , clayey silt & 1.0 & Soft plastic & 4.4 & 0.39 & 0.729 & $5 \times 10^{-4}$ \\
\hline 3 , mild clay & 1.5 & $\begin{array}{c}\text { Soft plastic or flow } \\
\text { plastic }\end{array}$ & 3.5 & 0.53 & 0.697 & $5 \times 10^{-5}$ \\
\hline 4, clayey silt & 5.0 & Soft plastic & 4.4 & 0.39 & 0.729 & $5 \times 10^{-4}$ \\
\hline
\end{tabular}

\section{Total Degree of Consolidation of Composite Foundation}

Based on the average degree of radial consolidation and vertical consolidation within the entire composite foundation, the average total degree of consolidation of composite foundation can be obtained by applying the Carrillo theorem [1], which can be expressed as follows:

$$
\bar{U}=1-\left(1-\bar{U}_{\mathrm{r}}\right) \cdot\left(1-\bar{U}_{\mathrm{z}}\right)
$$

where $\bar{U}$ denotes the average total degree of consolidation of the composite foundation.

\section{Engineering Application}

To assist geotechnical engineers in better utilizing the solutions presented in this paper, a comparison between the calculated results and measured results of an engineering application of expressway located in Zhengzhou City, Henan Province, China, is conducted in this section. The stone column composite foundation is adopted to improve the embankment of one section of this expressway, namely, section $k 60+730$, whose design drawing is similar to Figure 1 . Parameters of this composite foundation are as follows: $L=$ $8 \mathrm{~m}, d=0.5 \mathrm{~m}, n=2.7, s=1.4, k_{\mathrm{h}}=k_{\mathrm{v}}=4 \times$ $10^{-4} \mathrm{~m} / \mathrm{d}, k_{\mathrm{w}}=5 \mathrm{~m} / \mathrm{d}$, and $k_{\mathrm{s}}=4 \times 10^{-5} \mathrm{~m} / \mathrm{d}$. Meanwhile, parameters of the soil profile are shown in Table 1.

The relationship between load and time is illustrated in Figure 4, which can be simulated by a multistage loading model with two loading stages. The characteristic times of this loading model are $t_{1}=43 \mathrm{~d}, t_{2}=97 \mathrm{~d}$, and $t_{3}=184 \mathrm{~d}$, respectively. The loading rates of this loading model are $K_{\mathrm{el}}=$ $2 \mathrm{kPa} / \mathrm{d}$ and $K_{\mathrm{e} 2}=0.25 \mathrm{kPa} / \mathrm{d}$, respectively.

According to the soil profile, the vertical consolidation is considered to be double drainage. Based on the presented solutions, the time history of the average total degree of consolidation of composite foundation of section $k 60+730$ in this engineering application can be computed as shown in Figure 5. As it is evident from Figure 5, the trend of the calculated results matches very well with the measured results, which means that the solutions presented in this study have sufficient accuracy to predict the consolidation process of stone column composite foundation applied in enforcing the embankments of expressway.

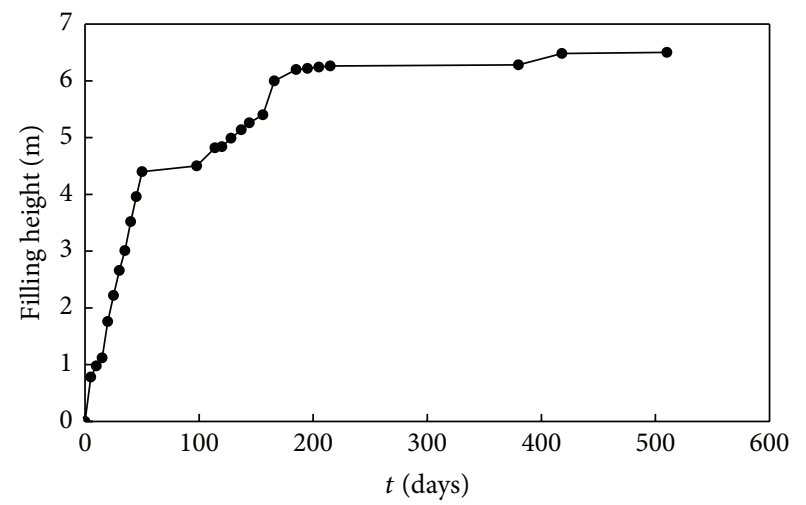

FIgURE 4: Relationship between load and time of section $k 60+730$.

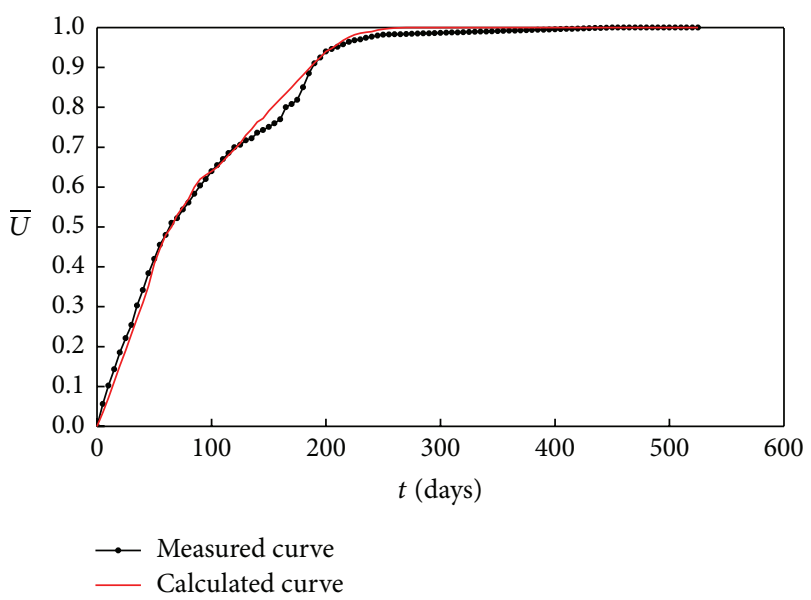

FIGURE 5: Time history of the average total degree of consolidation of composite foundation of section $k 60+730$.

\section{Conclusions}

Considering the relationship between loading and time, a closed-form theoretical solution was developed to solve the consolidation problem of a stone column composite foundation used in the enforcement of expressway embankments. Based on the calculation method for a sand drain well foundation, the consolidation problem of the composite foundation is divided into two portions, namely, radial consolidation and vertical consolidation. Based on the principle that the vertical load acting on the composite foundation 
is shared by the stone column and the surrounding soil, the governing equations for the radial consolidation and vertical consolidation are established by using a multistage load to simulate the boundary condition of expressway embankments. Then, the corresponding solutions for loading stage and maintaining load stage are subsequently derived by employing the separation of variables. Meanwhile, the solution for the average total degree of consolidation of entire composite foundation is also obtained by utilizing Carrillo theorem. Finally, an application example is conducted to help geotechnical engineers better adopt the present solution in predicting the consolidation process of a stone column composite foundation used in expressway embankments.

\section{Competing Interests}

The authors declare that they have no competing interests.

\section{Acknowledgments}

This research is supported by the National Natural Science Foundation of China (Grant nos. 51309207 and 51322807), the China Postdoctoral Science Foundation Funded Project (no. 2013T60759), the Research Funds provided by MOE Engineering Research Center of Rock-Soil Drilling \& Excavation and Protection (Grant no. 201402), and the Fundamental Research Funds for the Central Universities-Cradle Plan for 2015 (Grant no. CUGL150411).

\section{References}

[1] N. Carrillo, "Simple two and three dimensional case in the theory of consolidation of soils," Journal of Mathematics and Physics, vol. 21, no. 1-4, pp. 1-5, 1942.

[2] R. A. Barron, "Consolidation of fine-grained soils by drain wells," Transactions of American Society of Civil Engineers, vol. 113, no. 1, pp. 718-742, 1948.

[3] N. P. Balaam and J. R. Booker, "Analysis of rigid rafts supported by granular piles," International Journal for Numerical and Analytical Methods in Geomechanics, vol. 5, no. 4, pp. 379-403, 1981.

[4] C. C. Hird, I. C. Pyrah, and D. Russell, "Finite element modelling of vertical drains beneath embankments on soft ground," Geotechnique, vol. 42, no. 3, pp. 499-511, 1992.

[5] K. H. Xie, "Theory of one dimensional consolidation of doublelayer ground and its applications," Chinese Journal of Geotechnical Engineering, vol. 16, no. 5, pp. 24-36, 1994.

[6] G. J. Chen, "Consolidation of multilayered half space with anisotropic permeability and compressible constituents," International Journal of Solids and Structures, vol. 41, no. 16-17, pp. 4567-4586, 2004.

[7] J. Han and S. L. Ye, "A theoretical solution for consolidation rates of stone column-reinforced foundations accounting for smear and well resistance effects," International Journal of Geomechanics, vol. 2, no. 2, pp. 135-151, 2002.

[8] G. Zhu and J. H. Yin, "Consolidation analysis of soil with vertical and horizontal drainage under ramp loading considering smear effects," Geotextiles and Geomembranes, vol. 22, no. 1-2, pp. 63-74, 2004.
[9] G. C. Wang, "Consolidation of soft clay foundations reinforced by stone columns under time-dependent loadings," Journal of Geotechnical and Geoenvironmental Engineering, vol. 135, no. 12, pp. 1922-1931, 2009.

[10] J. Castro and C. Sagaseta, "Consolidation around stone columns: influence of column deformation," International Journal for Numerical and Analytical Methods in Geomechanics, vol. 33, no. 7, pp. 851-877, 2009.

[11] J. Castro and C. Sagaseta, "Deformation and consolidation around encased stone columns," Geotextiles and Geomembranes, vol. 29, no. 3, pp. 268-276, 2011.

[12] J. Castro, M. Karstunen, and N. Sivasithamparam, "Influence of stone column installation on settlement reduction," Computers and Geotechnics, vol. 59, pp. 87-97, 2014.

[13] K. H. Xie, M. M. Lu, A. F. Hu, and G. H. Chen, "A general theoretical solution for the consolidation of a composite foundation," Computers and Geotechnics, vol. 36, no. 1-2, pp. 24-30, 2009.

[14] M. M. Lu, K. H. Xie, S. Y. Wang, and C. X. Li, "Analytical solution for the consolidation of a composite foundation reinforced by an impervious column with an arbitrary stress increment," International Journal of Geomechanics, vol. 13, no. 1, pp. 33-40, 2013.

[15] M. M. Lu, K. H. Xie, C. X. Li, and K. Wang, "Consolidation solution for composite foundation considering a time- and depth-dependent stress increment along with three distribution patterns of soil permeability," Journal of Zhejiang University: Science A, vol. 12, no. 4, pp. 268-277, 2011.

[16] Y. P. Zhang, D. Chan, and Y. Wang, "Consolidation of composite foundation improved by geosynthetic-encased stone columns," Geotextiles and Geomembranes, vol. 32, pp. 10-17, 2012.

[17] X. W. Tang, B. Niu, G. C. Cheng, and H. Shen, "Closed-form solution for consolidation of three-layer soil with a vertical drain system," Geotextiles and Geomembranes, vol. 36, pp. 8191, 2013.

[18] T. Yang, J. Z. Yang, and J. Ni, "Analytical solution for the consolidation of a composite ground reinforced by partially penetrated impervious columns," Computers and Geotechnics, vol. 57, pp. 30-36, 2014.

[19] J. C. Liu, G. H. Lei, and M. X. Zheng, "General solutions for consolidation of multilayered soil with a vertical drain system," Geotextiles and Geomembranes, vol. 42, no. 3, pp. 267-276, 2014.

[20] I. Hosseinpour, M. Riccio, and M. S. S. Almeida, "Numerical evaluation of a granular column reinforced by geosynthetics using encasement and laminated disks," Geotextiles and Geomembranes, vol. 42, no. 4, pp. 363-373, 2014.

[21] S. G. Huang, "Analytical solutions for consolidation of composite ground with gravel piles under multi-grade loading in equal rates," Rock and Soil Mechanics, vol. 26, no. 1, pp. 199-202, 2005. 


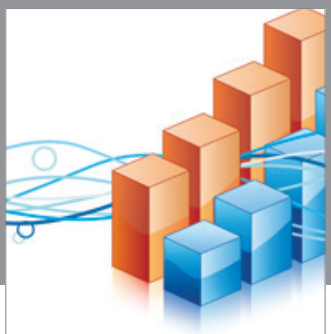

Advances in

Operations Research

vatem alat4

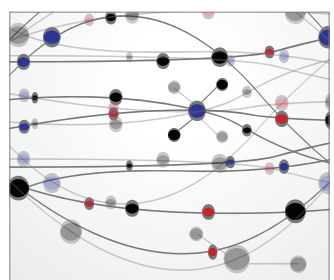

\section{The Scientific} World Journal
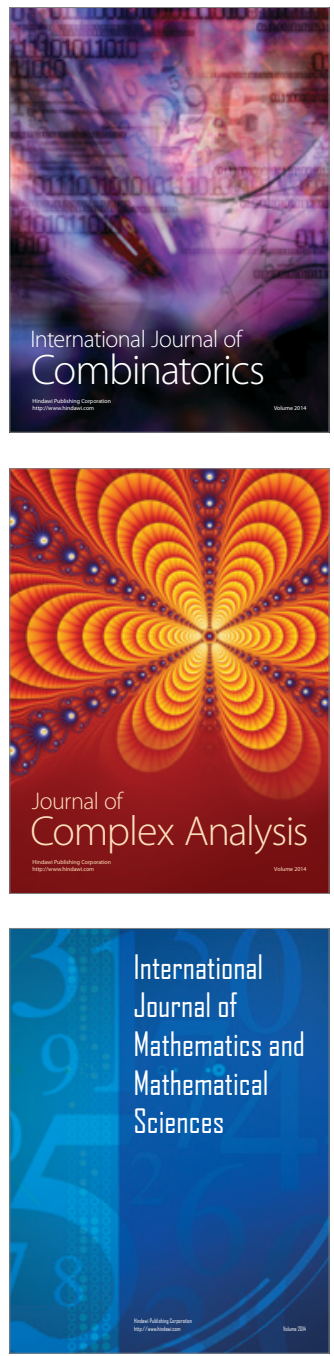
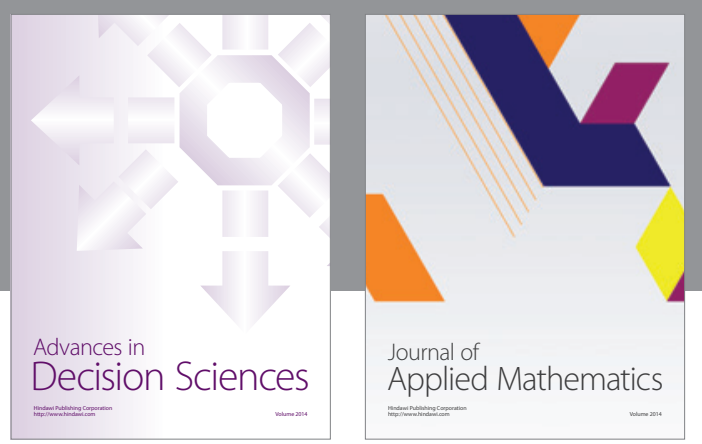

Algebra

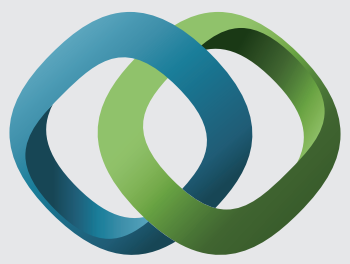

\section{Hindawi}

Submit your manuscripts at

http://www.hindawi.com
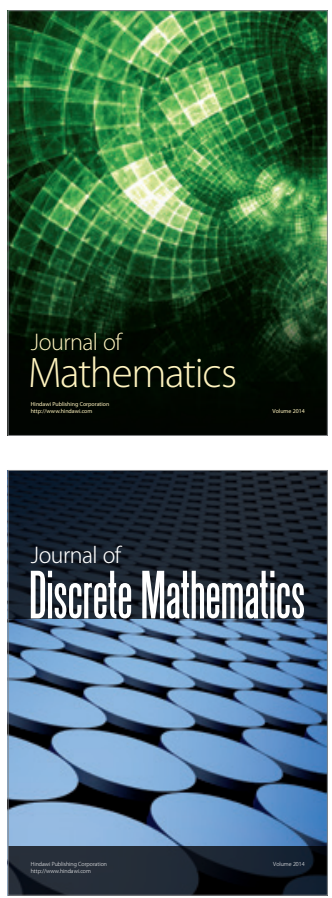

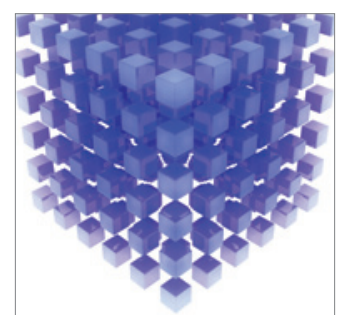

Mathematical Problems in Engineering
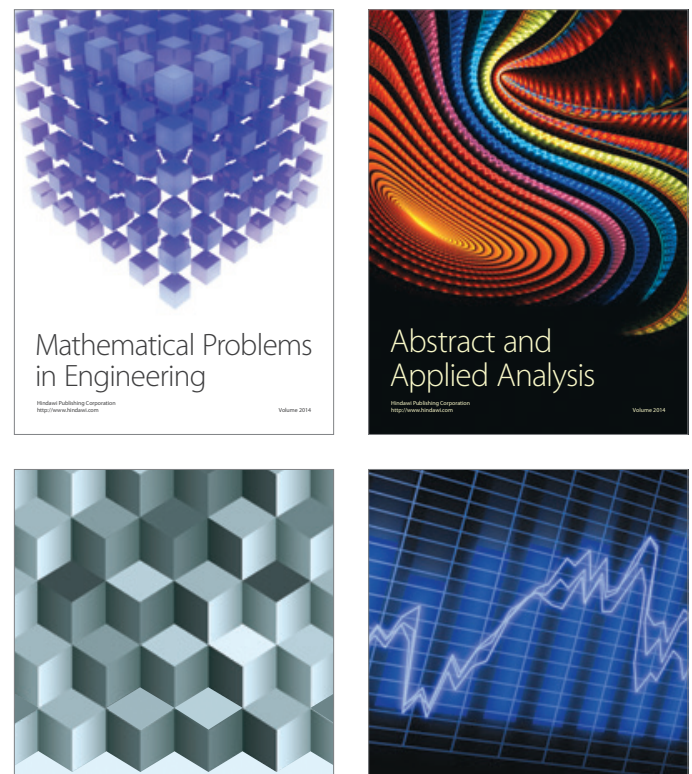

Journal of

Function Spaces

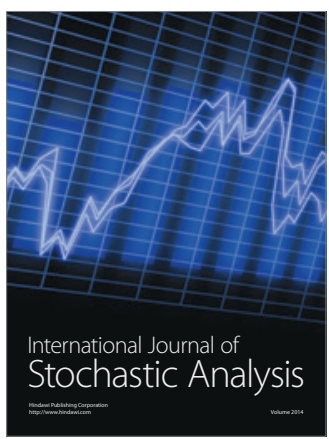

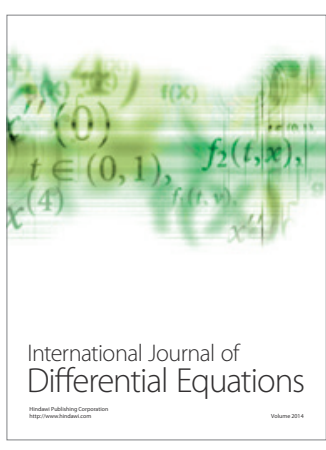
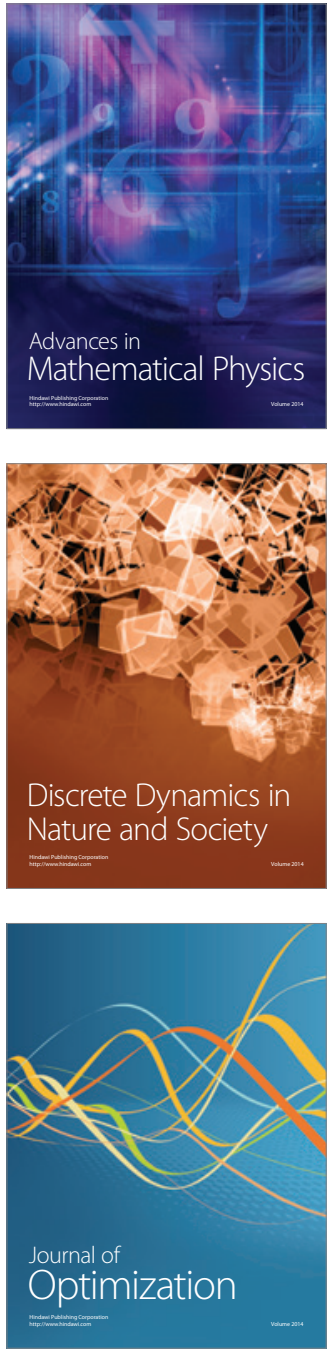